Supplement of Biogeosciences, 13, 1977-1989, 2016

http://www.biogeosciences.net/13/1977/2016/

doi:10.5194/bg-13-1977-2016-supplement

(C) Author(s) 2016. CC Attribution 3.0 License.

(c) (1)

Supplement of

\title{
Dead zone or oasis in the open ocean? Zooplankton distribution and migration in low-oxygen modewater eddies
}

Helena Hauss et al.

Correspondence to: Helena Hauss (hhauss@geomar.de)

The copyright of individual parts of the supplement might differ from the CC-BY 3.0 licence. 


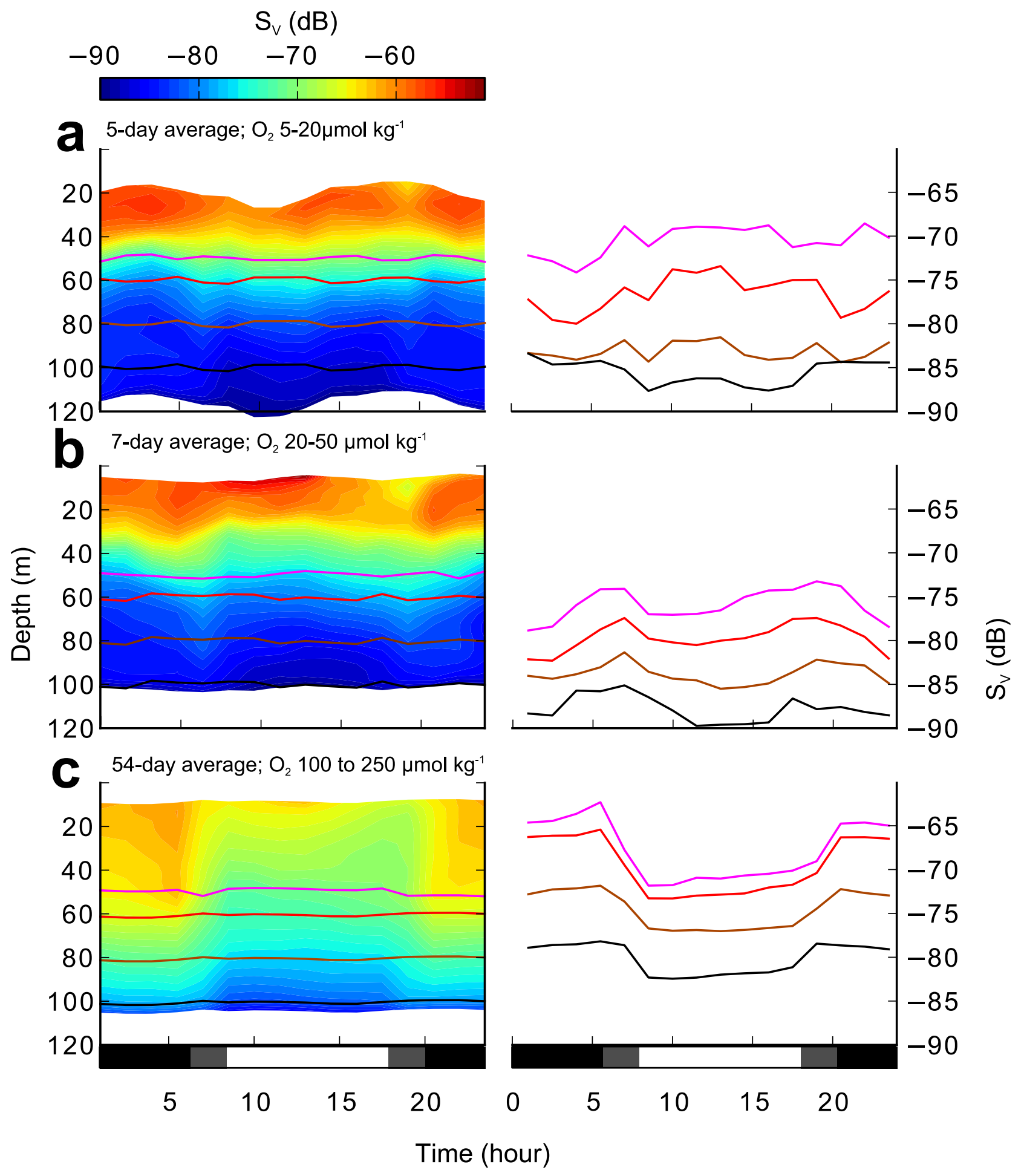

Figure S1: Daily cycles of moored ADCP mean volume backscatter Sv (dB) during transit of an ACME in 2010 (data from Jan 1 to Mar 14). Left: Depth-resolved contour plot of Sv over daytime; Data are averaged for days with a mean $\mathrm{O} 2$ concentration (at the depth of the moored $\mathrm{O} 2$ sensor, approximately $50 \mathrm{~m}$ ) below $20 \mu$ mol kg-1 (row A, n=5), 20$50 \mu \mathrm{mol} \mathrm{kg-1} \mathrm{(row} \mathrm{B,} \mathrm{n=7),} \mathrm{and} \mathrm{100-250} \mu$ mol kg-1 (row C, n=54). right: Sv at four different depth levels of approximately 50,60,80, and 100m; exact mean depth dependent on position of ADCP indicated by corresponding colored lines in the contour plots (left column). 
Table S1. Multinet-based abundance (ind $\mathrm{m}^{-3}$ ) for the five stations sampled during M105.

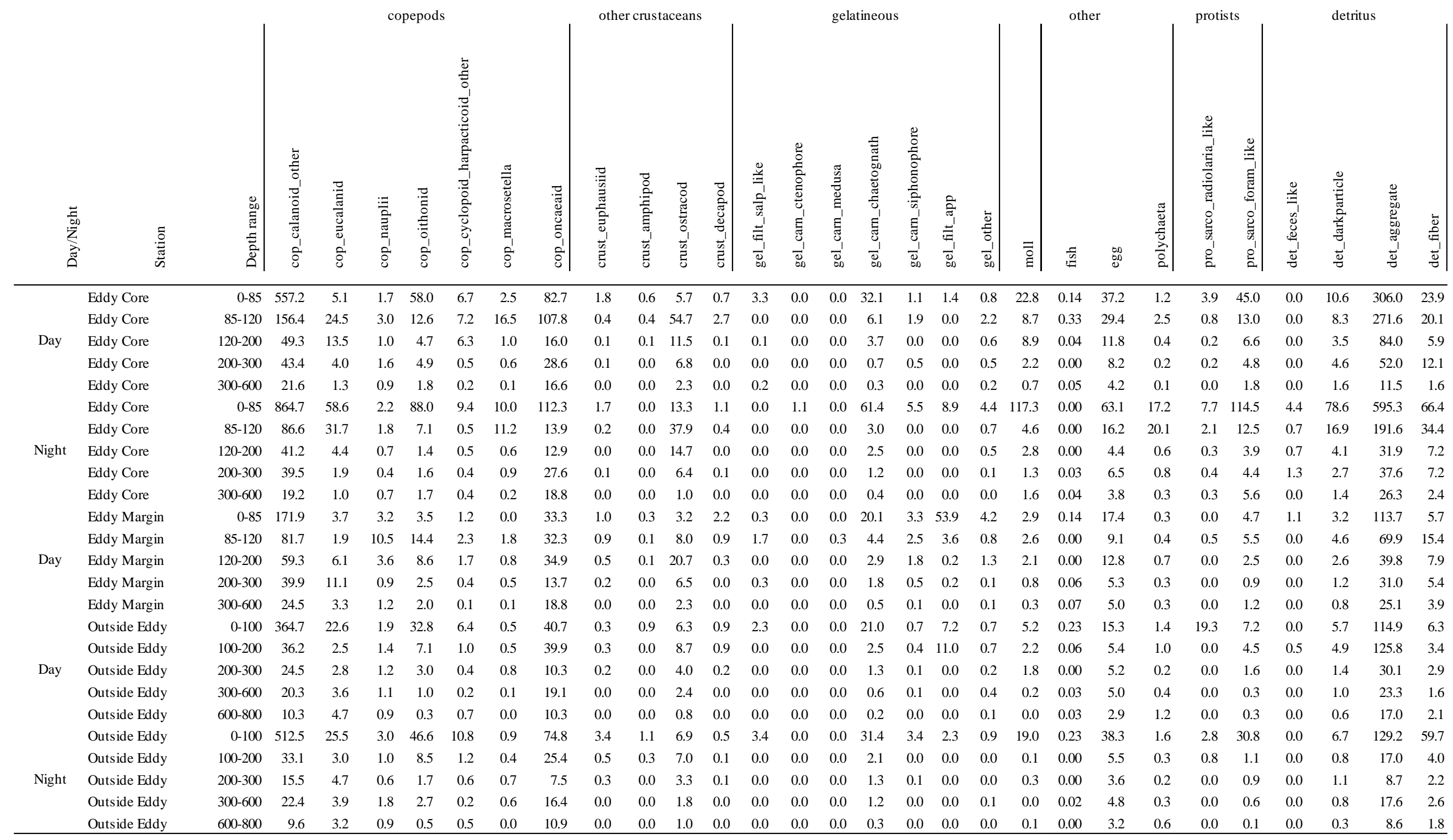


Table S2. Multinet-based integrated abundance (ind $\mathrm{m}^{-2}$, upper $600 \mathrm{~m}$ ) for the five stations sampled during M105.

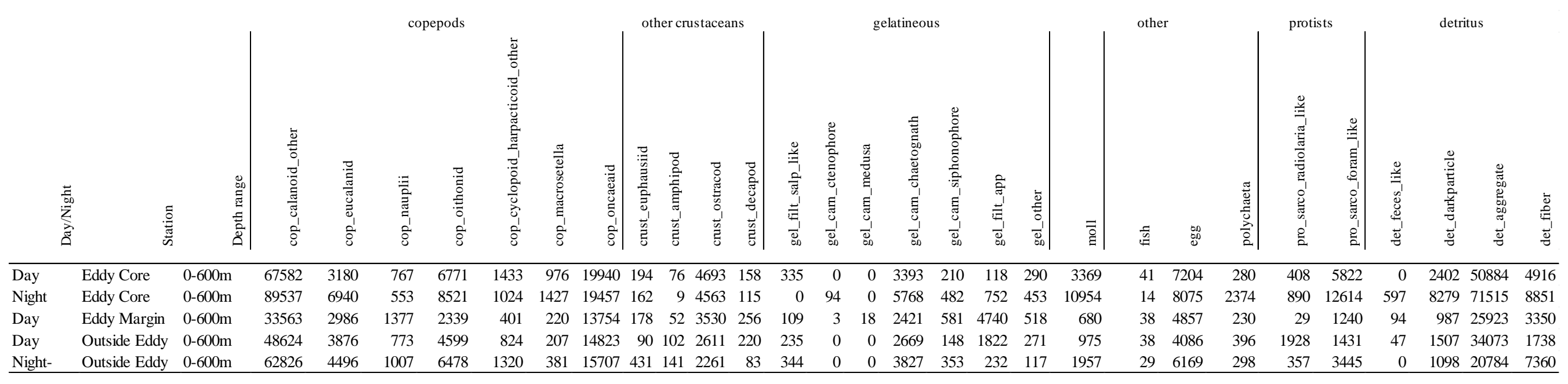

